Guerras culturais, batalhas alegóricas: entrelaçamentos do humor e do horror no cinema brasileiro contemporâneo

\author{
Culture wars, allegorical batles: entanglements of humor and horror \\ in contemporary Brazilian cinema
}

\title{
Diego Hoefel
}

Doutorando na Universidade NOVA de Lisboa. Pesquisador do CineLab (Laboratório de Cinema e Filosofia do Ifilnova - Instituto de Filosofia da NOVA), onde atualmente investiga as intersecções entre o humor e a ficção especulativa no cinema brasileiro contemporâneo, com subsídio da Fundação de Ciência e Tecnologia de Portugal (FCT) e do Fundo Social Europeu (FSE). Seus interesses incluem os estudos culturais e as relações entre a política, a mídia contemporânea e seus gêneros narrativos.

\section{Maria Irene Aparício}

Professora no Departamento de Ciências de Comunicação da NOVA FCSH - UNL, nas áreas de Cinema e Televisão, e Estudos Artísticos. É investigadora no CineLab (Laboratório de Cinema e Filosofia do Ifilnova - Instituto de Filosofia da NOVA), onde coordena o Grupo de Trabalho de "Cinema \& Política: Aproximações Filosóficas". O seu trabalho de pesquisa e reflexão está atualmente focado nas relações do cinema com as outras artes, e com as humanidades, nomeadamente nas temáticas da memória, ética e estética e respectivas dimensões filosóficas.

\section{RESUMO}

Uma linha de humor ancorada no imaginário do horror alastrou-se recentemente no cinema contemporâneo brasileiro. Bacurau, Clube dos Canibais e Exterminadores do Além contra a Loira do Banheiro são exemplos de filmes construídos em torno de conflitos entre dois lados opostos, dois extremos que se enfrentam violenta e cruelmente. Nesses enfrentamentos, há uma junção entre a ridicularização e o ataque do campo oponente muito próxima das dinâmicas das guerras culturais. Neste artigo, investigamos o entrelaçamento entre o humor e o horror nesses três filmes e discutimos sua possível conexão alegórica com o cenário de conflitos simbólicos que marca a sociedade brasileira ao longo dos últimos anos.

PALAVRAS-CHAVE: Guerras Culturais. Cinema Contemporâneo. Humor. 


\section{ABSTRACT}

A strain of humor anchored in the imaginary of horror has recently spread in Brazilian contemporary cinema. Bacurau, The Cannibal Club and Ghost Killers vs. Bloody Mary are examples of films that focus on conflicts between two opposing sides, two extremes that combat each other violently and cruelly. In these confrontations, there is a junction of mockery and attack of the opposing side similar to the dynamics of the culture wars. In this paper, we examine the intertwining of humor and horror in these three films and discuss their possible allegorical connection to the scenario of symbolic conflicts that has marked Brazilian society over the past few years.

KEYWORDS: Culture Wars. Contemporary Cinema. Humor. Horror.

Apesar de estimularem sensações e afetos aparentemente opostos, a comédia e o terror foram conjugados com espantosa frequência ao longo da história do cinema. Gremlins (1984), Ghostbusters (1984) e Pânico (1996) são exemplos de grande notoriedade (Carroll, 1999; Yogerst, 2016), mas a fusão do humor e do horror também está presente em filmes mais recentes, como Zombieland (2009), Mother! (2017) e Get Out (2017) (Carew, 2019; Bishop, 2011; Rubenstein, 2019). Esse encontro pode parecer insólito e intrigante à primeira vista, pois o público tem de um lado uma expectativa de descontração e riso e, do outro, de assombro e tensão crescente. No entanto, ambos lidam com a "violação, a problematização e a transgressão de categorias, normas e conceitos" (Carroll, 1999, p. 152), o que pode explicar sua afinidade. Quando discute o subgênero terror-comédia, Noel Carroll identifica uma intercalação entre momentos de leveza, marcados pela presença de piadas e pelo uso de comic timing; e outros de vigília, em que se soma à narrativa tensão e medo. Essa alternância faz com que a audiência pareça estar em algumas cenas diante de uma comédia, e, em outras, diante de um filme de terror. A mobilização (ou não) do medo é uma boa forma de se explicar essa cadência de estados discutida por Carroll. Contudo, ela não se aplica ao humor sádico de alguns filmes produzidos recentemente no Brasil. Nesses textos culturais, o público experimenta um estado simultâneo de divertimento e de medo. Ao invés de oscilar entre a comédia e o terror, os filmes parecem conjugá-los. 
Uma convergência similar entre medo e comicidade também pode ser identificada nas reações de diversos setores da sociedade brasileira a processos de moralização social ocorridos especialmente ao longo dos últimos cinco anos, no que se convencionou chamar de "onda conservadora" (Almeida, 2020). Nesse período, uma intensa polarização social fez com que os dois extremos do espectro político se atacassem mutuamente, ora sugerindo a periculosidade do oponente, ora descreditando-o comicamente. A eleição de Jair Bolsonaro em 2018 reforça essa conjunção entre temor e zombaria. Quando ainda deputado federal e depois candidato, Bolsonaro havia sempre reiterado uma profunda contrariedade ao trabalho de organizações não-governamentais, movimentos sociais e à luta pelos direitos humanos (de populações LGBTQIA+, negras, indígenas, etc.). Sua vitória foi tomada com profundo receio pelos setores progressistas da sociedade, como a possibilidade iminente de ataques a quaisquer pessoas que divergissem (mesmo que por sua mera existência) da pauta de defesa dos costumes construída a partir da coligação entre a extrema-direita e a igreja evangélica (Almeida, 2019). Ao mesmo tempo, a aparente inabilidade do novo líder de estado para o cargo e suas gafes frequentes motivaram um sem-número de memes, imitações, e esquetes de stand-up comedy. Em muitos casos, o deboche construía-se justamente a partir do perigo potencial representado pela ascensão ao poder de um presidente de ultradireita. Um misto entre tensão e riso.

Nesses anos de adensamento da polarização e de belicosidade potencial, foram produzidos textos culturais bastante singulares na tradição recente do cinema brasileiro. São filmes em que há muitas cenas de derramamento de sangue, uma profusa e intensa violência gráfica. Focamos esta discussão em três obras: Bacurau (2019), Clube dos Canibais (2018) e Exterminadores do Além contra a Loira do Banheiro (2018). Em cada uma dessas narrativas, é possível identificar a presença de dois lados opostos, dois extremos que se enfrentam até à morte. Mas as cenas de embate desses filmes não são apenas assustadoras, elas são também cômicas. Acreditamos que esses embates ficcionais estão intimamente 
relacionados ao conjunto de conflitos simbólicos presentes na sociedade brasileira atual, tanto discursiva quanto formalmente.

Não é nova a ideia de que existe, na produção cultural latino-americana em geral (Shohat e Stam, 2006; Avelar, 2003) e no cinema brasileiro em específico (Xavier, 2013), uma tendência para se recorrer à alegoria como forma de representação dos contextos sociopolíticos locais, em especial em situações de crise. De forma muito simplificada, é essa a tese que defende Ismail Xavier quando propõe a alegoria como conceito unificador para uma produção bastante heterogênea surgida no Brasil no final da década de 1960, época em que a ditadura civil-militar passou por um processo de endurecimento - com um fortalecimento da censura e das perseguições políticas. Mas se na época da ditadura os discursos precisavam ser cifrados - tanto para fugir à censura, quanto para proteger suas autoras e seus autores -, atualmente não ocorre o mesmo. O Brasil está atravessado por guerras culturais em que os valores de cada um dos polos opostos são constante e abertamente confrontados, ora pelo viés da ridicularização, ora pelo do medo.

Dado que essas duas tendências - tanto o deboche, quanto a suspeita - vêm sendo amplificadas no panorama atual de constantes conflitos simbólicos (Nagle, 2017), o nosso argumento central é de que a combinação entre o humor e o horror vem ganhando destaque no cinema brasileiro contemporâneo como uma tradução alegórica das guerras culturais. Para abordar essa questão, na primeira seção examinamos a recente retomada de importância das alegorias no cinema brasileiro contemporâneo. Na sequência, discutimos as novas guerras culturais e o papel das culturas online no impulso das ações de demonizar e ridicularizar os oponentes. Por fim, na última seção, investigamos como filmes brasileiros recentes que mesclam humor e horror representam a situação sociopolítica atual do país. 


\section{0 retorno às alegorias nacionais}

A alegoria pode ser esquematicamente definida como uma "ficção contada de tal forma a indicar, por semelhança devidamente sugestiva, uma estrutura clara de ideias não ficcionais" (Teskey, 2006, p. 300). Trata-se de uma estratégia de representação em que se constrói narrativamente uma determinada situação com o propósito de se abordar outra. 0 termo é derivado da expressão grega allēgoria, que significa "falar de outra maneira" (junção entre allos, "outro", e agoreuein, "falar em público"). Existe uma longa tradição de discussões sobre a alegoria e sua relação com o papel interpretativo do público (Bloomfield, 1972); o "jogo" (Teskey, 2006, p. 307) que se estabelece no processo de decodificação, ou de "reestruturação do texto" (Honig, 2018, p. 29) ocorrido durante a recepção. Não vamos nos concentrar nesses debates, até porque os filmes que aqui analisamos (e abordaremos isso com mais detalhes na seção 3) não impõem grandes desafios hermenêuticos à audiência. Interessa-nos, sobretudo, pensar essa categoria em diálogo com algumas leituras modernas que a recuperam com o intuito de definir como determinados textos culturais problematizam experiências coletivas a partir de representações indiretas do contexto sociopolítico em que estão inseridos.

Ismail Xavier (2013) defende que o surgimento de novas formas no cinema brasileiro das décadas de 1960 e 1970 pode estar conectado ao cenário turbulento da ditatura civil-militar. Os filmes incluídos em sua análise foram produzidos principalmente a partir de 1968, quando o Congresso Nacional brasileiro foi dissolvido, a antiga Constituição abandonada e as liberdades civis suprimidas. A hipótese de Xavier é de que esse conjunto de profundas transformações políticas foi internalizado na construção formal dos filmes e mobilizou "estratégias alegóricas marcadas pelo senso da história como catástrofe" (2013, p. 14). Ele investiga uma constelação bastante diversa de textos culturais, todos produzidos aproximadamente na mesma época, e identifica em cada um mecanismos específicos de construção alegórica. Suas conclusões indicam uma possível relação 
entre o uso preferencial da alegoria como ferramenta de representação e o sentimento coletivo de crise, presente naquele momento em particular ${ }^{1}$.

O subdesenvolvimento é considerado um tema central nos textos culturais produzidos nesse período, algo que já aparece indicado no próprio título do livro de Xavier, Alegorias do Subdesenvolvimento. Nas palavras do autor, trata-se do reconhecimento de uma "condição dramática" (2013, p. 16) que se opõe ao "imperativo da industrialização tal como conduzido nos termos da modernização conservadora consolidada a partir do golpe de 1964" $(2013,17)$. A aposta do governo militar na industrialização é vista como o desejo de ser o que não se é. 0 terceiro mundo que almeja converter-se em primeiro. Em contrapartida, o termo "alegorias do subdesenvolvimento" sistematiza uma discussão sobre traços particulares do Brasil, algo que remonta com frequência - muitas vezes como uma das chaves interpretativas dos textos - ao histórico da colonização. Trata-se de um conceito bastante próximo ao de "alegorias nacionais" proposto por Jameson (1986), inclusive no que concerne à relação entre alegoria e as especificidades culturais dos países periféricos.

Após o final do regime militar, o recurso alegórico continuou a ser utilizado no cinema brasileiro. Ivana Bentes (2007) identifica a construção de microcosmos alegóricos do país nos espaços tanto do sertão quanto da favela, ambos representados em profusão no cinema da década de 1990. Essa ideia vai na mesma direção do que propõe Katia Maciel (2009) sobre a imagem do sertão em Lisbela e o Prisioneiro (2003), mas é o contrário do que defende Adalberto Müller (2006) em sua análise sobre Cinema, Aspirinas e Urubus (2005). Segundo o autor, no filme o sertão deixa de ser "a alegoria de um país dilacerado social e politicamente [como o representara a ficção do período ditatorial], para ser o cenário de troca de experiências, afetivas sobretudo" (Müller, 2006, p. 6). Já Angela Prysthon (2006)

\footnotetext{
${ }^{1}$ Idelber Avelar parte de um argumento semelhante sobre o luto e o fracasso para compor o que compreende como "alegorias da derrota" na ficção pós-ditatorial latino-americana (2003). Também não muito distante está ideia de "alegorias da impotência", de Ella Shohat e Robert Stam (2006).
} 
reconhece, em road movies latino-americanos como Terra Estrangeira (1993), Diários de Motocicleta (2003) ou Y tu Mamá También (2001), tanto elementos que compõem uma espécie de "alegoria continental" quanto os que exploram "jornadas interiores" dos personagens similares às que Müller ressalta em sua análise. Em todas essas investigações o foco central está no uso dos espaços (a favela, o sertão, os "entrelugares" dos deslocamentos) como sínteses alegóricas do país ou do continente; e não na relação entre a alegoria e as especificidades do momento sociopolítico de sua produção. Elas não indicam, portanto, nem uma articulação entre condicionantes históricas particulares, nem uma adesão coletiva ao emprego de recursos alegóricos, como fizera Xavier no período ditatorial.

Recentemente, embora decerto o contexto seja outro, uma nova articulação entre a emergência de construções alegóricas e o adensamento de um cenário sociopolítico turbulento começou a ser reconhecida na academia brasileira (Hora, 2020; Setubal, 2018; Ferreira, 2017). Discussões frequentes no país, relacionadas ao lugar de fala, ao racismo estrutural, à diversidade sexual e à herança colonial vêm sendo transpostas para a composição de microcosmos ficcionais em diversos textos culturais. Além disso, o interesse na discussão sobre as especificidades do subdesenvolvimento e sua transposição no estabelecimento de relações de poder usados para caracterizar a produção cultural dos anos 1960 e 1970 também podem ser estendidos a esse conjunto de obras audiovisuais, em que a alegoria volta a ser utilizada como recurso para se discutir (e problematizar) modos de operação específicos do país. Existe, no entanto, uma diferença fundamental entre essas novas alegorias e as do período ditatorial: se ali Xavier identifica uma construção em alguns casos próxima ao drama barroco (2013, p. 63), e em outros à paródia (2013, p. 130), aqui acreditamos que uma chave importante na construção alegórica dos textos seja a presença de um hibridismo entre elementos e códigos de diferentes gêneros cinematográficos.

Esse hibridismo é particular a cada texto cultural. Em alguns casos, há uma junção entre terror, ficção científica e comédia romântica, como na série original

Dossiê Guerras Culturais - https://revistaecopos.eco.ufri.br/

ISSN 2175-8689-v. 24, n. 2, 2021

DOI: 10.29146/ecopos.v24i2.27699 
do Netflix Boca a Boca (2020) (Prisco, 2020). Em outros, a fusão ocorre entre ficção científica e faroeste, como em Era uma Vez Brasília (2017) (Hora, 2020), ou entre drama e terror, como em Todos os Mortos (2020) (Mourinha, 2020). Neste artigo, focamo-nos na junção insólita entre a comédia e o terror, que pode ser identificada nos três filmes aqui em análise, mas também em diversos outros, como O Animal Cordial (2017), As Boas Maneiras (2017) e M 8 (2020), apenas para citar alguns. A centralidade do recurso alegórico em todas essas obras corrobora a ideia de que há, de fato, um novo momentum para esse tipo de construção no cinema contemporâneo brasileiro, algo que pode ser reconhecido em um conjunto bastante heterogêneo de textos culturais recentes, de maneira semelhante ao que ocorrera no período ditatorial.

Conforme apontado anteriormente, uma possível explicação para esse retorno às alegorias nacionais é o recente fortalecimento do conservadorismo, algo que se evidenciou tanto no impeachment de Dilma Rousseff quanto na vitória eleitoral de Bolsonaro - que chegou a ser lida como uma "nova virada autoritária" (Neiburg e Thomaz, 2020). Shohat e Stam identificam, nos regimes repressivos, um uso exagerado de uma já existente tendência alegórica, motivado por um sentimento de obrigação das realizadoras e dos realizadores de "falar para e sobre a nação como um todo" (2006, p. 391). As alegorias seriam, assim, um recurso cultural especialmente proeminente em momentos de crise e de expressiva inquietação social e política, dada a sua capacidade de sintetizar impasses nacionais. Foi, como vimos, o que aconteceu durante a ditadura civil-militar, de acordo com a tese clássica de Xavier. E é também o que nos parece estar a ocorrer agora, em resposta aos processos intensos de polarização e de moralização social que tomaram o país nos últimos anos, ambos diretamente conectados às guerras culturais.

Ao longo do artigo, iremos discutir como esse retorno às alegorias nacionais pode ser relacionado com as diferentes convergências entre a comédia e o terror. Antes de entrar mais propriamente nessa questão, parece-nos importante 
aprofundar um pouco a discussão sobre as guerras culturais. 0 termo, já amplamente consolidado nos Estados Unidos, tem sido hoje tomado de empréstimo pela academia brasileira como referência a uma série de polêmicas que amplificam uma já intensa polarização social e repercutem em constantes fissuras na opinião pública. Interessa-nos partir da constatação de que existem guerras simbólicas hoje em curso no país, principalmente para refletir sobre como esse contexto socialmente belicoso vem sendo traduzido pelo cinema brasileiro contemporâneo.

\section{Guerras culturais, batalhas alegóricas}

Segundo James Davison Hunter, que é tido como o pioneiro das discussões sobre as guerras culturais na década de 1990, o que configura esse fenômeno em uma determinada sociedade não é apenas a presença de impasses morais, mas o seu agenciamento como um "impulso polarizador" (Hunter, 1991, p. 43). Como se pode imaginar, esses impulsos são reduzidos basicamente a dois: em um dos polos há uma tendência à ortodoxia (ou ao conservadorismo); no outro, ao progressismo. A maior parte das autoras e dos autores que identifica a existência de guerras culturais no Brasil contemporâneo parte de uma definição não muito distinta desta (Goldstein, 2019), e não raro tem como embasamento principal a própria definição de Hunter (Gallego, et al., 2017; Souza e Azevedo, 2018).

No entanto, há diferenças significativas entre as guerras culturais de hoje e as que o autor descreve nos Estados Unidos dos anos 1990. Por essa razão, alguns estudos recentes preferem o termo novas guerras culturais (Daum, 2019; Campbell; Manning, 2018; Castle, 2018) para caracterizar especificamente os conflitos atuais, marcados pela "migração do discurso político para as redes sociais" (Serpe, 2019, p. 101). No ambiente virtual, as guerras culturais não somente passaram a ter uma maior disseminação, mas foram também intensificadas por um tipo de engajamento customizado, possível a partir da recomendação personalizada de conteúdos. São as chamadas bolhas (Recuero, et 
al., 2017), que se formam tanto pelo conjunto restrito de interações entre cada rede de contatos, quanto pelo rastreio de informações que permite às plataformas sugerir determinados produtos culturais a cada usuária ou usuário com base em seus interesses anteriores. Os critérios de seleção desses conteúdos são feitos por algoritmos que tentam prever sua relevância potencial para um determinado perfil, o que faz com que a maior parte das pessoas acabe apenas -exposta a conteúdos que reiteram (ou até radicalizam) suas crenças². Assim, os "impulsos polarizadores" das novas guerras culturais tendem a ser ainda mais extremados do que em décadas anteriores, levando países como o Brasil e os Estados Unidos a uma profunda cisão social. Além disso, há novos fenômenos em curso, como a cultura do cancelamento (Ng, 2020) e a cultura da vitimização (Campbell; Manning, 2018). Em ambas, ações coletivas de hostilidade são colocadas em prática como forma de resistência de um grupo a um inimigo em comum, tomado como representativo de um conjunto de microagressões sistêmicas (Fatima, 2017) que se quer erradicar.

Todo esse conjunto de fatores soma-se na constituição de um cenário social notadamente belicoso; o que não se limita aos espaços virtuais. No Brasil, tornaram-se frequentes os cartazes que pedem uma nova intervenção militar e a volta da ditadura nas manifestações da extrema-direita (Novaes, 2015). Jair Bolsonaro, quando ainda deputado federal, apresentou seu voto favorável ao impeachment de Dilma Rousseff, após fazer uma homenagem a um coronel que a torturou durante os anos mais sombrios do regime ditatorial (Jiménez, 2016). Também há diversos incidentes de pessoas que foram espancadas apenas por estarem na rua usando roupas de cor vermelha (Rossi, 2015), algo que era tomado como sendo um sinal de adesão ao polo progressista. Na sociedade brasileira

\footnotetext{
2 Essa relação entre as culturas online e o processo de radicalização das crenças de usuárias e usuários foi discutido no documentário O Dilema das Redes (2020) e também amplamente analisado em relatórios recentes, como o do instituto norte-americano Data \& Society, especialmente no que tange às relações entre a normalização de discursos extremistas, a manipulação da mídia e a desinformação online (Marwick; Lewis, 2017).
}

Dossiê Guerras Culturais - https://revistaecopos.eco.ufrj.br/

ISSN 2175-8689-v. 24, n. 2, 2021

DOI: 10.29146/ecopos.v24i2.27699 
ocorre, portanto, uma progressiva contaminação entre a prática política e as ações e discursos de ódio, tanto nas redes quanto fora delas. Essa aproximação não se limita apenas à arena política tradicional (Gallego, 2018; Gledhill, 2019). Ela é identificada também no domínio privado, isto é, na casa, na família, na igreja, nas relações entre amigos, vizinhos, etc. (Pinheiro-Machado; Scalco, 2018; Solano, 2019).

Os três textos culturais a que nos referimos especialmente aqui foram produzidos nesse contexto profundamente beligerante. Nos três, há construções narrativas que se encaminham para um grande conflito final, uma batalha em que dois lados opostos medem suas forças violentamente. 0 embate varia em cada texto: um grupo de caçadores de fantasmas que enfrenta uma assombração engajada cinicamente em discursos progressistas e utiliza a agenda feminista como uma estratégia de vitimização (Exterminadores do Além contra a Loira do Banheiro); um zelador negro que protege a própria vida do canibalismo dos patrões, brancos e ricos (Clube dos Canibais); ou uma comunidade do nordeste brasileiro que se defende de um conjunto de atiradores norte-americanos, cujo hobby é assassinar pessoas do sul global como se estivessem em um videogame (Bacurau). Por essa descrição sucinta já se pode perceber o quanto esses textos jogam com elementos específicos das guerras culturais (e.g. a vitimização, o racismo, o imaginário colonial) para ficcionalmente aniquilarem os personagens que representam o polo oposto ao defendido por cada filme, com direito a muito sangue, explosões e cabeças cortadas.

Mas, como já dissemos, há também humor na maneira como cada um dos textos apresenta esses enfrentamentos. Em um filme abertamente conservador como Exterminadores do Além contra a Loira do Banheiro, a incursão pelo terror é intercalada por piadas politicamente incorretas, em que os protagonistas (todos homens) atacam a militância feminista e queer, e a reduzem a estratégias de vitimização. Em textos progressistas como Clube dos Canibais e Bacurau, o alvo das operações cômicas é a hipocrisia das elites. Nesses filmes, os vilões agem de forma 
profundamente questionável em termos éticos, ao mesmo tempo em que defendem discursos de moralização social.

Essa junção entre os conflitos simbólicos e o humor também aproxima esses textos das novas guerras culturais hoje em operação no país. Ao longo dos últimos anos, a internet transformou-se em um espaço importante de militância e de confronto de ideias e, ao mesmo tempo, em um ambiente "saturado de ironia" (Nagle, 2017, p. 17). Os memes são um bom exemplo. Eles passaram a ter um relevante poder discursivo na sociedade contemporânea (Wiggins, 2019; Shifman, 2014) e têm motivado diversos estudos, inclusive no Brasil, sobre sua possível influência em processos eleitorais (Barros; Milanezi, 2020) e também na assimilação cotidiana dos impasses surgidos no campo político (Freire, 2016). Ao contrário das guerras culturais da década de 1990, em que um grupo composto em sua maioria por conservadores mais velhos "lutou contra uma maré de secularização cultural e liberalismo entre os jovens" (Nagle, 2017, p. 10), os embates dos últimos anos não se restringem mais fundamentalmente a conflitos geracionais. Angela Nagle identifica uma tendência a um ultraconservadorismo jovem nas redes sociais, capaz de mobilizar "uma estranha vanguarda de gamers adolescentes, amantes de anime com pseudônimo de suástica, (...) antifeministas jocosos, nerds assediadores e criadores de memes de trollagem" $(2017$, p. 11). 0 que os une é o recurso ao humor como estratégia de depreciação do polo oposto, algo que também se verifica na direção contrária, dos progressistas em relação aos conservadores.

O que configura e define as novas guerras culturais não é apenas o caráter polêmico dos temas pautados, mas também seus modos específicos de engajamento e constituição comunitária, para os quais o humor pode agir como um catalisador (Purdie, 1993; Gillespie, 2004). Se as batalhas alegóricas presentes nos três filmes aqui em foco são transposições dos conflitos simbólicos nacionais para cada microcosmo ficcional, acreditamos que essa tradução não se limite ao conteúdo das discussões, mas envolva também o tom no qual elas se desenvolvem. 
Por isso, assim como nas redes, os textos culturais também parecem saturados de uma ironia estranha, um tipo de humor sádico ou doentio, que acaba por convocar o tratamento de temas delicados como a morte, a sexualidade, as relações de poder e todo o conjunto de preconceitos que divide hoje a sociedade brasileira.

\section{Comédia, terror e violência gráfica}

Nas diversas críticas publicadas em resposta ao lançamento de Bacurau nas salas de cinema brasileiras, é frequente a menção a um conjunto de reações de exaltação (incluindo gritos, aplausos, gargalhadas, etc.) durante a sua sequência mais brutal (Bernardes, 2019; Magnoli, 2019). Enquanto na tela os vilões norteamericanos eram mortos e decapitados um a um, nas salas de cinema parte do público comemorava, vibrava. Esse curto-circuito entre a representação violenta da morte de um lado e, de outro, uma resposta prazenteira e festiva parece espelhar o conjunto de reações que motivaram Paul Lewis a escrever sobre o que chamou de killing jokes (1997), um fenômeno identificado na produção cultural norte-americana da década de 1980. Nessa época, personagens como Freddy Krueger no cinema, e o Coringa nos quadrinhos, tensionavam os limites entre a comédia e o terror na medida em que fugiam da imagem clássica do vilão monstruoso e não se limitavam a torturar e assassinar suas vítimas, mas também faziam piadas, brincavam, divertiam-se com cada assassinato - e com isso divertiam também o público. Lewis coleta relatos da época, em que, lá também, a crítica parecia estupefata com "os gritos e risadas altas no clímax da violência”, o que levava a crer que "o público percebia [os muitos atos de crueldade dos filmes] como uma comédia" (Ebert, 1981, p. 54 apud Lewis, 1997, p. 252).

Esse estado de divertimento somente é possível porque nos filmes não há conflito moral na representação das mortes. Nöel Carroll aproxima essa placidez à comédia, em que a preocupação pelo bem-estar dos personagens é dissipada (1999, p. 158). No registro cômico, a morte perde o seu peso, o que explica a naturalidade da inclusão de desenhos animados como Papa-léguas (Wile E. Coyote 
and the Road Runner) ou Tom \& Jerry na grade de programação infantil, apesar de seu storyline resumir-se a tentativas frustradas do personagem mais forte capturar o mais fraco, geralmente seguidas de caos, destruição e morte. Quando Tom, o gato de Tom \& Jerry, fere-se seriamente, ou quando o Coiote de Papa-léguas cai uma e outra vez de distintos desfiladeiros, a audiência ri ao invés de preocupar-se com a integralidade física dos personagens. E ri não somente por serem os vilões a morrer $^{3}$, ri porque há um enquadramento cômico que não convida a que se meça "o peso moral ou humano das consequências" (Ibidem, p. 158) do sofrimento do outro. Apesar de as mortes ocorrerem, elas não são sentidas exatamente como óbitos; é como se acontecessem numa espécie de "espaço de sonho" (Lahikainen, 2015, p. 104). É o somatório dessa desimportância e dessa ausência de repercussões no nível da narrativa que torna o humor possível.

Quando as fronteiras entre a comédia e o terror se confundem, uma forma de investigar a presença das operações cômicas é analisar se a representação da morte é usada como elemento de revigoramento do medo, ou como algum tipo de deboche cruel. Se for este o caso, o texto cultural convida à fruição de cenas de derramamento de sangue com menos opressão e gravidade do que no terror clássico, o que pode causar estouros comemorativos nas salas de cinema, como os que indignaram parte da crítica nas exibições de Bacurau. Não apenas neste filme, mas em todos os três aqui discutidos, há uma ausência de peso e seriedade na representação de situações de extermínio em massa. Contudo, ao contrário dos desenhos animados, essas mortes não são apenas sugeridas, elas são explícita e violentamente representadas. Isso perturba o "espaço dos sonhos" da comédia ao afirmar a materialidade de cada morte. 0 único humor possível, neste caso, é um

\footnotetext{
${ }^{3}$ Um exemplo célebre de um não-vilão cuja morte é composta como uma piada recorrente é Kenny McCormick, de South Park. Nas cinco primeiras temporadas da série, Kenny morre em praticamente todos os episódios, muitas vezes de forma extremamente violenta e gráfica; e depois reaparece vivo e bem no episódio seguinte.
} 
humor negro 4 ou doentio (do inglês sick humor), em sua específica conjugação de riso e ansiedade (Beermann, 2014; Mindess, et al., 1985).

Um outro elemento que reitera a afinidade entre a comédia e o terror é a presença de construções alegóricas. Nessas obras, os personagens que morrem violenta e cruelmente não são apenas vilões. Num filme conservador como Os Exterminadores do Além contra a Loira do Banheiro, o espírito contra quem os caçadores de fantasma precisam lutar revela-se como a reencarnação de uma menina que, quando viva, fazia-se passar por feminista e politicamente correta para atormentar a vida dos colegas. Essa descoberta associa a vilã à cultura de vitimização, uma leitura proposta pela extrema-direita acerca do ativismo em defesa de políticas identitárias. Ela ecoa ações de "misoginia digital" (BanetWeiser; Miltner, 2016; Salter; Blodgett, 2017) usadas para combater a popularização do feminismo, e com isso reforça a agenda conservadora do filme. No outro oposto do espectro ideológico, Clube dos Canibais e Bacurau retratam seus vilões como uma elite de capitalistas brancos, heterossexuais e cisgênero. Os heróis desses dois relatos são pessoas racializadas, pobres, oprimidas e abertamente alinhadas à luta por um Brasil inclusivo e plural, ou seja, claras personificações de pautas progressistas. Nos três textos, os personagens (tanto os heróis, quanto os vilões) encarnam alegoricamente temas exaustivamente discutidos ao longo dos últimos anos no contexto das guerras culturais. Isso faz com que os monstros sejam percebidos simultaneamente como os vilões da narrativa e como avatares de um conjunto de atores políticos associados a um ou a outro posicionamento. Assim, sua morte violenta não é sentida apenas como o término de uma ameaça no nível do relato, mas também como uma vingança

\footnotetext{
${ }^{4}$ Reconheço a dificuldade do emprego do termo "humor negro" pela utilização da palavra "negro" como algo insultuoso ou depreciativo. No entanto, o "humor negro" é um conceito cunhado na história dos estudos de humor e conjuga uma já considerável bagagem de discussões. Na falta de uma melhor tradução, mantenho a referência a essas discussões, contudo pontuo a necessidade de se repensar e problematizar a nomenclatura.
} 
simbólica, uma extinção sarcástica, cruel e sangrenta dos inimigos de cada um dos lados.

Se tomarmos, por exemplo, as obras produzidas no período ditatorial latinoamericano, em muitos casos a alegoria foi utilizada como um recurso alusivo para se discutir problemas nacionais, uma espécie de "camuflagem protetora contra regimes censores" (Shohat; Stam, 2006, p. 390). Nesse tipo de construção, a audiência é convidada a destrinchar a mensagem para compreender a que exatamente ela se refere, como se o texto fosse uma espécie de jogo projetado pela autora ou pelo autor para o seu público (Teskey, 2006, p. 314). Decifrar o conteúdo seria vencer o jogo, reestruturar o texto para compreender exatamente como os elementos do microcosmo ficcional se relacionam com os do cenário macropolítico. Na contramão dessa tendência, Gordon Teskey identifica em algumas alegorias marcadas por uma forte carga satírica a presença de construções deliberadamente claras, ou seja, mensagens pouco ou quase nada codificadas, criadas com o fim de gerar um entendimento inequívoco. Nessas obras, o que gera prazer não é o jogo interpretativo, mas "a oportunidade de brincar com os termos de comparação" (Ibidem, p. 296, grifo nosso). Isso parecenos bastante propício para descrever esses três textos culturais, em que, inclusive por ecoar discussões já consolidadas em conflitos simbólicos recentes, a representação alegórica é construída de forma deliberamente direta e simplória. Ocorre, no entanto, que os termos de comparação não são quaisquer. Os adversários de cada campo político são representados como monstros ou como psicopatas e a brincadeira é exterminá-los, ver seu sangue explodir na tela. Algo, como diria Lahikainen, "profundamente horrível e potencialmente engraçado ao mesmo tempo" (2015, p. 95).

Isso faz com que essas obras sejam duplamente chocantes: primeiro por esbanjarem uma intensa violência gráfica no nível do relato, depois (e talvez principalmente) por essa violência ser extensível alegoricamente a determinados grupos ou atores sociais. Mas a brutalidade e a selvageria são fundamentais para 
que esses textos possam construir seus inimigos como seres possivelmente extermináveis. Trata-se, conforme propõe Freud, de uma técnica de insulto que retrata os adversários como pessoas pequenas, inferiores, desprezíveis, a quem a audiência, caso se alinhe ideologicamente ao filme, tem satisfação de sobrepujar, mesmo que por via indireta $(2017,149)$. É a ficcionalização dessa vitória potencial, seja ela um "otimismo ingênuo" (Obrdlik, 1942, p. 710) ou não, que permite a conversão simbólica “da impotência em poder, da vítima em predador" (Lewis, 1997, p. 276).

\section{Considerações Finais}

Há diversos estudos que relacionam as imbricações entre humor e violência às especificidades de cada contexto de produção. Um exemplo são as charges produzidas na Inglaterra em reação à Revolução Francesa. Amanda Lahikainen (2015) identifica nesses textos culturais uma notória articulação do humor e do horror. 0 medo e a repugnância passaram a ser utilizados como forma de construção cômica, o que incluía imagens caricaturais de cabeças cortadas, canibalismo, forcas, guilhotinas e muito derramamento de sangue. Esses artifícios "intensificam gêneros híbridos e revelam uma obsessão pela morte e pela ironia, todas formas modernas de lidar com a turbulência social que se desenrolava então na França" (Lahikainen, 2015, p. 96). Um outro exemplo são as piadas de matar de Freddy Krueger e do Coringa. Para Paul Lewis, as killing jokes podem ser associadas a uma "crescente apreensão coletiva acerca da vulnerabilidade da raça humana no contexto de riscos e perigos globais" (Lewis, 1997, p. 253), algo que começou a ser discutido na década de 1980, com a divulgação de estudos sobre o buraco da camada de ozônio, as mudanças climáticas e os diversos impactos da ação humana na destruição do meio ambiente. Frente a esse contexto, rir de mortes coletivas a partir de textos culturais ao mesmo tempo sombrios e engraçados seria uma maneira, segundo Lewis, de melhor suportarmos nosso fim iminente (pela própria destruição da Terra). Mais recentemente, Angela Nagle 
identifica um ciclo de piadas iniciado após a viralização do vídeo da morte do gorila Harambe em um jardim zoológico norte-americano. No vídeo, vê-se o gorila ser baleado, após apertar e arrastar um menino de três anos de idade que havia escalado para dentro de sua jaula. De acordo com Nagle, "responder a tragédias altamente mediadas com ironia e anedotas insensíveis tem sido uma marca das culturas de trollagem online" (2017, p. 17), um tipo específico de humor que a autora conecta diretamente ao fortalecimento das novas guerras culturais. Nos três casos, fica claro que certos contextos sociopolíticos favorecem o desenvolvimento, aumentam a tolerância e/ou instauram o gosto por manifestações de um tipo de humor sádico, que congrega o humor ao horror e à violência.

Esse tipo de humor sádico também pode ser identificado em filmes brasileiros recentes. Nessas narrativas, as novas guerras culturais são traduzidas para o que aparece narrativamente também como uma guerra, mas composta por batalhas de fato. Isso ocorre porque os polos rivais da realidade e seus atores sociais são materializados em personagens ficcionais a partir de operações alegóricas. Esses personagens não somente se opõem no campo das ideias; eles efetivamente lutam uns contra os outros em disputas violentas, de vida ou morte. Assim, os conflitos simbólicos do país são representados de forma concreta. Nas alegorias, eles deixam de ser embates morais e passam a ser combates corpóreos, físicos. Os filmes traduzem os dilemas de um país polarizado e atravessado por guerras culturais em combates alegóricos, transformando a morte daqueles que representam os antagonistas políticos de cada lado em uma mistura de zombaria, alívio do medo e entretenimento sádico a partir da violência gráfica.

Mas a relação dessas obras com as guerras culturais não se limita a essa transposição narrativa. Ela também se concretiza de fato, uma vez que os filmes foram distribuídos comercialmente e assim inseridos no conjunto de embates simbólicos em processo no país. Em outras palavras, as guerras culturais existem no interior dos filmes (enquanto operação alegórica), mas também são 
reabastecidas a partir deles (como consequências estético-políticas). Isso é reforçado pelo fato de suas narrativas serem estruturadas em torno de piadas de matar, e funcionarem através de interações com elementos do humor negro e do humor doentio, ambos notoriamente utilizados com o fim de chocar a audiência.

As operações cômicas que "extraem o seu impacto da violação de tabus", diz Paul Lewis, "são recebidas por muitas pessoas como ofensivas (...) e convidam a respostas extremas, ou de divertimento ou de ódio" (Lewis, 1997, p. 254). Esse extremismo parece ser uma boa forma de definir as possibilidades de adesão ou de repúdio desencadeadas por cada uma dessas narrativas, e também de pensar o quanto elas reiteram uma já existente polarização - sem efetivamente contribuir para sensibilizar a parcela do público que não concorda previamente com o posicionamento político de cada filme. Assim, as obras parecem insistir no que cada um dos polos das guerras culturais já defende e acredita. Elas apostam no adensamento dos conflitos, não em sua problematização ou eventual resolução. Esse adensamento ocorre não somente a partir das operações simbólicas dos filmes, mas também de sua própria inserção nas guerras culturais, como veículo articulado com os ataques de determinado campo político contra seus adversários.

Se, como afirma Christie Davies, as piadas não são "termostatos sociais que regulam e moldam o comportamento humano, mas (...) termômetros que medem, gravam e indicam o que está acontecendo" (1997, p. 9), a emergência de formas de humor marcadas pelo sadismo denota tradicionalmente momentos de turbulência sociopolítica. As recentes alegorias brasileiras das guerras culturais parecem validar essa premissa. Essas narrativas, como argumentamos, são nutridas de um híbrido de humor e horror. Mas essa conjunção não se restringe à ficção; ela também reflete sentimentos coletivos sobre o conjunto de hostilidades que marcaram a sociedade brasileira nos últimos anos. A cada novo fato político, a cada escândalo, a cada virada inesperada, ou declaração descabida, um sentimento ao mesmo tempo de repulsa e de chacota instala-se no país - e isso em ambos os lados, tanto entre progressistas, quanto entre conservadores. "É rir para não 
chorar", diz o provérbio popular brasileiro. Talvez esse ditado resuma um conhecimento adquirido, uma espécie de resiliência depois de séculos de opressão, décadas de ditadura e recentes novas ameaças a uma jovem e frágil democracia. Nesses filmes, contudo, não há uma substituição do choro pelo riso, mas sim o surgimento de um riso cruel, uma comicidade doentia substanciada na agonia e no padecimento do outro. A cultura reflete o tempo em que se desenvolve. "Se algo está doente", diz Alan Dundes, "é a própria sociedade que produz o humor doentio" (2017, p. 11).

\section{Referências bibliográficas}

ALMEIDA, R. Bolsonaro presidente: conservadorismo, evangelismo e a crise brasileira. Novos Estudos: Cebrap, p. 185-213, Jan.-Abr. 2019.

. The broken wave: Evangelicals and conservatism in the Brazilian crisis. HAU: Journal of Ethnographic Theory, p. 32-40, 2020.

AVELAR, I. Alegorias da Derrota: A ficção pós-ditatorial e o trabalho do luto na América Latina. Belo Horizonte: Editora UFMG, 2003.

BANET-WEISER, S.; MILTNER, K. \#MasculinitySoFragile: culture, structure, and networked misogyny. Feminist Media Studies, v. 16(1), p. 171-174, 2016.

BARROS, L. M.; MILANEZI, M. J. D. F. Disputas simbólicas em memes das eleições presidenciais brasileiras de 2018. Lumina, p. 174-191, 2020.

BEERMANN, U. Sick Humor. In: ATTARDO, S. Encyclopedia of Humor Studies. Los Angeles: Sage, 2014. p. 691-693.

BENTES, I. Sertões e favelas no cinema brasileiro contemporâneo: estética e cosmética da fome. Revista Alceu, p. 242-255, 2007.

BERNARDES, M. Brasil e a Catarse de um País Desesperado. Gazeta Arcadas, 02 Out 2019. Disponível em: <https://gazetaarcadas.com/2019/10/02/bacurau-e-a-catarse-de-umpais-desesperado/>. Acesso em: 17 Nov 2020.

BISHOP, K. Vacationing in "Zombieland": The Classical Functions of the Modern Zombie Comedy. Journal of the Fantastic in the Arts, p. 24-38, 2011.

BLODGETT, B.; SALTER, A. Ghostbusters is For Boys: Understanding Geek Masculinity's Role in the Alt-right. Communication Culture \& Critique, v. 11, p. 133-146, 2018.

BLOOM, E. A. The Allegorical Principle. ELH, v. 18, p. 163-190, 1951.

BLOOMFIELD, M. Allegory as Interpretation. New Literary History, p. 301-317, 1972.

Dossiê Guerras Culturais - https://revistaecopos.eco.ufrj.br/

ISSN 2175-8689-v. 24, n. 2, 2021

DOI: 10.29146/ecopos.v24i2.27699 
CAMPBELL, B.; MANNING, J. The Rise of Victimhood Culture: Microaggressions, Safe Spaces, and the New Culture Wars. Cham: Palgrave Macmillan, 2018.

CAREW, A. American horror: Genre and the post-racial myth in 'get out'. Screen Eduacation, p. 14-21, 2019.

CARROLL, N. Horror and Humor. The Journal of Aesthetics and Art Criticism, p. 145-160, 1999.

CASTLE, J. New Fronts in the Culture Wars? Religion, Partisanship, and Polarization on Religious Liberty and Transgender Rights in the United States. American Politics Research, p. 1-30, 2018.

DAUM, M. The Problem with Everything: My Journey Through the New Culture Wars. New York: Gallery Books, 2019.

DAVIES, C. Ethnic Humor Around the World: A Comparative Analysis. Bloomington: Indiana University Press, 1997.

DUNDES, A. Cracking Jokes: Studies of Sick Humor Cycles \& Stereotypes. New Orleans: Quid Pro, 2017.

FATIMA, S. On the Edge of Knowing: Microaggression and Epistemic Uncertainty as a Woman of Color. In: COLE, K.; HASSEL, H. Surviving Sexism in Academia: Feminist Strategies for Leadership. New York and London: Routledge, 2017. p. 147-157.

FERREIRA, C. Refletindo sobre golpes duros e brandos: uma comparação de Aquarius de Kleber Mendonça Filho e Terra em Transe de Glauber Rocha. Revista Brasileira de Estudos do Cinema e Audiovisual, p. 4-43, 2017.

FREIRE, F. Uma Breve Reflexão sobre Memes Políticos, Humor e Conversação Cotidiana Informal. Em Debate, p. 34-40, 2016.

FREUD, S. O Chiste e sua Relação com o Inconsciente. São Paulo: Companhia das Letras, $2017 / 1905$.

GALLEGO, E. S. O Ódio como Política: a reinvenção das direitas no Brasil. São Paulo: Boitempo, 2018.

GALLEGO, E. S.; ORTELLADO, P.; RIBEIRO, M. M. Guerras culturais e populismo antipetista nas manifestações por apoio à Operação Lava Jato e contra a reforma de previdência. Em Debate, p. 35-45, 2017.

GILLESPIE, M. From Comic Asians to Asian Comics: Goodness Gracious Me, British Television Comedy and Representations of Ethnicity. In: SCRIVEN, M.; ROBERTS, E. Group Identities on French and British Television. Oxford: Berghahn Books, 2004. p. 93-108.

GLEDHILL, J. Capitalism, the politics of hate, and everyday cosmopolitanisms. Critique of Anthropology, p. 1-19, 2019.

GOLDSTEIN, A. O Sucesso das "Guerras Culturais" na Campanha 2018: Bolsonaro no Facebook e Instagram. Inter-Legere, 2019.

HONIG, E. Dark Conceit: The Making of Allegory. Evanston: Northwestern University Press, 2018.

Dossiê Guerras Culturais - https://revistaecopos.eco.ufrj.br/

ISSN 2175-8689-v. 24, n. 2, 2021

DOI: 10.29146/ecopos.v24i2.27699 
HORA, T. Corpos Interditos em Era um Vez Brasília. Campo Grande. 2020.

HUNTER, J. D. Culture Wars: the struggle to define America. New York: Basic Books, 1991.

JAMESON, F. Third-World Literature in the Era of Multinational Capitalism. Social Text, p. 65-88, 1986.

JIMÉNEZ, C. Um retrato do torturador comandante Brilhante Ustra, segundo as suas vítimas. El País, 22 abr 2016. Disponível em:

<https://brasil.elpais.com/brasil/2016/04/20/politica/1461180363_636737.html>. Acesso em: 26 set 2020 .

LAHIKAINEN, A. "Some Species of Contrasts": British Graphic Satire, the French Revolution, and the Humor of Horror. Humor, v. 28 (1), p. 93-117, 2015.

LEWIS, P. The Killing Jokes of the American Eighties. Humor, p. 251-283, 1997.

MÜLLER, A. Cinema (de) novo, estrada, sertão: notas para (se) pensar Cinema, aspirinas e urubus. Logos 24, p. 1-7, 2006.

MACIEL, K. Beyond Stereotype and Comedy: the 'pop' and the 'modern' Brazil on screen. Lusophonie, p. 27-40, 2009.

MAGNOLI, D. Tréplica: Em 'Bacurau', cinema deixa interesse público, segregando-se na bolha do Partido. Folha de São Paulo. 17 set 2019.

MARWICK, A.; LEWIS, R. Media Manipulation and Disinformation Online. Data \& Society Research Institute, 2017.

MINDESS, H. et al. The Antioch Sense of Humor Test: Making Sense of Humor. New York: Avon Books, 1985.

MOURINHA, J. Berlim e os fantasmas do passado (do Brasil, da Galiza e de todo o lado). Jornal O Público, 24 Fev 2020. Disponível em:

<https://www.publico.pt/2020/02/24/culturaipsilon/noticia/berlim-fantasmaspassado-brasil-galiza-lado-1905318>. Acesso em: 26 mar. 2021.

NAGLE, A. Kill All Normies: Online Culture Wars from 4Chan and Tumblr to Trump and the Alt-Right. Winchester and Washington: Zero Books, 2017.

NEIBURG, F.; THOMAZ, O. Ethnographic views of Brazil's (new) authoritarian turn. HAU: Journal of Ethnographic Theory, p. 7-11, 2020.

NG, E. No Grand Pronouncements Here.: Reflections on Cancel Culture and Digital Media Participation. Television \& New Media, p. 621-627, 2020.

NOVAES, M. Quando o 'chorume' da internet invade a vida real. El País, 19 ago 2015. Disponível em:

<https://brasil.elpais.com/brasil/2015/08/18/opinion/1439908643_894361.html>. Acesso em: 26 set 2020.

OBRDLIK, A. J. "Gallows Humor"-A Sociological Phenomenon. American Journal of Sociology, p. 709-716, 1942.

Dossiê Guerras Culturais - https://revistaecopos.eco.ufrj.br/

ISSN 2175-8689-v. 24, n. 2, 2021

DOI: 10.29146/ecopos.v24i2.27699 
PINHEIRO-MACHADO, R.; SCALCO, L. M. Da esperança ao ódio: a juventude periférica bolsonarista. In: GALLEGO, E. O Ódio como Política: a reinvenção das direitas no Brasil. São Paulo: Boitempo Editorial, 2018.

PRISCO, L. "Boca a Boca é sobre o vírus do conservadorismo", diz diretor Esmir Filho. Metrópoles, 28 Set 2020. Disponível em: <https://www.metropoles.com/entretenimento/televisao/boca-a-boca-e-sobre-o-virusdo-conservadorismo-diz-diretor-esmir-filho>. Acesso em: 26 mar. 2021.

PRYSTHON, A. Da Alegoria Continental às Jornadas Interiores: o road-movie latinoamericano contemporâneo. Ícone, p. 113-124, 2006.

PURDIE, S. Comedy: the mastery of discourse. Toronto: University of Toronto Press, 1993.

RECUERO, R.; ZAGO, G.; SOARES, F. B. Mídia Social e Filtros-bolha nas Conversações Políticas no Twitter. Anais dos Encontros da Compós. São Paulo: Associação Nacional dos Programas de Pós-Graduação em Comunicação. 2017.

ROSSI, M. Protestos anti-PT registram agressões a quem veste camiseta vermelha. El País, 17 ago 2015. Disponível em: <https://brasil.elpais.com/brasil/2015/08/17/politica/1439769515_800304.html>. Acesso em: 26 set 2020.

RUBENSTEIN, D. "An Actual Nightmare, but... Pretty Good TV": Horror-comedy in the Trump Era. In: WEBBER, J. The Joke Is on Us: Political Comedy in the (late) Neoliberal Times. Lanham: Lexington Books, 2019. p. 267-292.

SALTER, A.; BLODGETT, B. Toxic geek masculinity in media: Sexism, trolling, and identity policing. Cham: Palgrave MacMillan, 2017.

SERPE, N. The New Tech Culture Wars. Dissent, p. 101-110, 2019.

SETUBAL, M. Distopia e reparação política na Ceilândia de Adirley Queirós. Urbana, p. 570591, 2018.

SHIFMAN, L. Memes in Digital Culture. London: MIT Press, 2014.

SHOHAT, E.; STAM, R. Crítica da Imagem Eurocêntrica: multiculturalismo e representação. São Paulo: Cosac Naify, 2006.

SOLANO, E. A bolsonarização do Brasil. In: ABRANCHES, S. Democracia em crise? 22 ensaios sobre o Brasil hoje. São Paulo: Companhia das Letras, 2019.

SOUZA, M. F. C.; AZEVEDO, N. P. D. S. G. Guerras Culturais e Formações Imaginárias da Polarização Política Brasileira: um estudo discursivo. Humanidades \& Inovação, p. 209226, 2018.

TESKEY, G. Allegory. In: HAMILTON, A. C. The Spenser Encyclopaedia. London: Routledge, 2006. p. 300-362.

WIGGINS, B. The Discursive Power of Memes in Digital Culture. New York and London: Routledge, 2019.

XAVIER, I. Alegorias do Subdesenvolvimento: Cinema Novo, Tropicalismo, Cinema Marginal. São Paulo: Cosac Naify, 2013.

Dossiê Guerras Culturais - https://revistaecopos.eco.ufrj.br/

ISSN 2175-8689-v. 24, n. 2, 2021

DOI: 10.29146/ecopos.v24i2.27699 
YOGERST, C. Rules for Surviving a Horror Comedy: Satiric Genre Transformations from Scream to Zombieland. In: MILLER, C.; VAN RIPER, B. The Laughing Dead: The HorrorComedy Film from Bride of Frankenstein to Zombieland. Lanham: Rowman \& Littlefield, 2016. p. 169-186. 